\title{
On Cohen's Critique of Technology and Social Justice
}

\author{
Li Yong ${ }^{1}$, Zhang Yi ${ }^{2}$ \\ ${ }^{1}$ Marxist Philosophy Institute, Shanxi University, Taiyuan, China \\ ${ }^{2}$ Philosophy, School of Humanities, University of Glasgow, Glasgow, UK
}

Email address:

themythone@sxu.edu.cn (Li Yong),2344350z@student.gla.ac.uk (Zhang Yi)

\section{To cite this article:}

Li Yong, Zhang Yi. On Cohen's Critique of Technology and Social Justice. Advances in Sciences and Humanities. Vol. 5, No. 2, 2019, pp. 43-48. doi: 10.11648/j.ash.20190502.11

Received: December 6, 2018; Accepted: January 10, 2019; Published: April 12, 2019

\begin{abstract}
It is supposed that to be just in society is the intrinsic pursuit of Marxist theory in Marx's original text. While as the result of historical context, according to Marx, the just society can be realized in a far future. Cohen holds materialism standpoint to illustrate historical materialism creatively by functional explanation in the modern history context. In a new time with much more advanced science and technology, he is keeping going with the route of Marxism for overcoming the technique alienation and argues that in order to realize freedom, equality and justice, appealing to empirical critique of technology and exploration of social theory is essential. The demonstration of that freedom, equality and justice are compatible, which is a cornerstone of practical just social theory. As Cohen is in the analytical tradition, his creative functional explanation presents obvious empiricism and analytical character. He digs out the key of resolving problem of development in moral dimension apart from the materialism, and conducts the argument to attack the political designs, which separates free distribution in market, quality in society, and just spirit from each other. This essay is intended to figure out Cohen's argument that is based on the traditional Marxism and stand, while points out a new way to help people reach the just society at the much more near future.
\end{abstract}

Keywords: Justice, Functional Explanation, Critique

\section{Introduction}

Marx acknowledged that "only if we accumulate adequate material capital", then the just could come; while he also located the feasibility into remote ideal. Therefore, Cohen, aiming to modify this thought, try his best to explore a new path, which grantss opportunity for realizing just in social based on current conditions, and provides proofs for its possibility, actuality and feasibility. In Cohen's mind, we can realize this aim on the current situation by means of combination of technology critique, how to deal with the relationship between technology and human nature, as well as social critique, rethinking whether social system could be running more reasonable.

\section{The Functional Explanation Historical Materialism}

There is a claim, by Marx, in the preface of Critique of
Political Economy: "The whole process of social life, political life, and mental life is restrained by the productive method of material life. It is not the case that thought determines the existence; in contrast, the existence determines thought. If the force of production had developed at the certain stage, then it would be not compatible with the previous relationships of production or property. At this moment, the given relationships would become the limitation of the productive force and the social revolution comes at this period" [15]. We can refine a proposition that: the productive force determines the productive relationships by Marx's words. Marx's economic interpretation for history and the dualistic viewpoint have been challenged by modern thought.

\subsection{The Modern Challenge to Marxist Materialism}

In the modern tendency, there is a challenge to system of knowledge and history. Some proposals held by philosophers are helpful to figure out various dominant factors. As the result of finding the interval features, Anthony Giddens thinks that the reflective usage of knowledge system makes its 
certainty undergo the scrutiny and being modified. Karl Popper said, "All of the science are established on the flow of sand". E P Thompson, following empirical tradition, pays a lot of attention to crux, by designing a "social existence-experience-social idea" interactive mode, in order to eliminate the distinction between social existence and social idea. Therefore, the history could not be regarded as the natural science ruled by universal principle or model. Regarding to David Harvey, temporal objects cause the continuity of history is difficult to be reserved, and his history-geography materialism has opened the space thinking, that means the space contains double senses including ontology and methodology, even the time is inside it, that is to say the space is the "speaker" of our era. The current changes has been described by Milan Kundera, in "The Book of laughter and Forgetting" in a poem tune: "currently, time goes forward harshly, so that the so-called historical event will be forgotten overnight. The sunlight in the morning also fad away with the dew, therefore, it has not been playing the role as the background in stories of narrator, rather a piece of legend in front of common private lives. History is fading away from memories [13]."

Does the historical materialism still well-establish under the rush of modern thoughts? Cohen answered yes. The first step is to clarify the concept of historical materialism. In his mind, "the historical materialism" [15] is a positivism theory that related to social structure and power of historical evolution. By means of functional interpretation, he rewrote the story of historical materialism based on "the productive force determines the relationships of production". The functional interpreted historical materialism is an updated-version of the traditional.

\subsection{The Functional Explanation Historical Materialism}

In functional interpretation, the feature of interpreted item is explained by the explaining item. For example, birds having hollow bone because it is helpful for flying; the shoes factory product shoes in a large scale is the result of that large scale production will produce economic benefit. The functional explanation confer the reason to why the empirical facts in nature and economic life can run continuously. How can it explain how productive force put forward the historical development? This question can be transformed into whether it is consistent with the law of causality? We try to compare it with the Humean causality to work out the question. Let letter $\mathrm{E}$ for reason and letter $\mathrm{F}$ for result. In accordance with the definition of functional explanation, the reason why $\mathrm{E}$ happens is that it will trigger $F$, i.e. $(E \rightarrow F) \rightarrow E$. Then the question has been converted into whether " $\rightarrow$ "indicate "implication"?

Hume, in "On the Probable Inference: and On the Notion of causality", proposed that: "the purposes of inferences are comparing and figuring out the constant and variant relationships between two or more facts [12]." The reason why causality could be the basis of inference is that in accordance with it we can find out the former or later objects/events of the current empirical phenomenon. Only if a result acquires proper proof it could become belief, which means the result deriving from causality playing the role of premise. Causality, as a probable inferring method, is contained in logic that pursues certainty. Hume [12] told us that the notion of causality is the source of reason and effect, at the same time, this notion deriving from the constant link of impression-notion: "comparing between ideas produces certainty, whose another source is steady relationship". Overall, Human causality has following features: (1) the objects linked by causality have close spatial and temporal relationships;(2) reason is in front of result temporally;(3)continuity among reasons and corresponding results. The latest character unfolds in time, basing on experience that beyond our perception, which also implies that if something could be experienced, it will have opportunity to become impression planting into mind.

Then we inlet the time variable $t$ into the above formula can get following result:

$$
(\forall \mathrm{x})(\mathrm{E}(\mathrm{x}, \mathrm{t} 1) \rightarrow(\mathrm{y}) \mathrm{F}(\mathrm{y}, \mathrm{t} 2)) \rightarrow((\mathrm{z}) \mathrm{E}(\mathrm{z}, \mathrm{t} 3)) .
$$

As it illustrates that time variable $\mathrm{t} 1, \mathrm{t} 2$ and $\mathrm{t} 3$ are not in the fixed order, which covers the second character of Humean causality; simultaneously, the continuity of history could be found in historical materialism as well; then the close relationships among individual constants spatially in the functional explanation reflects the first feature. Above all, we could, in a general meaning, acknowledge functional explanation is consistent with Humean causality. Although Hume goes from notion of causality to scepticism ultimately, when the black-box of induction has not been unblocked, the fruitful achievements from natural science defend its rationality.

From chart 1, the functional explanation is consistent with empiricalism

Table 1. The value of functional explanation.

\begin{tabular}{lllll}
\hline & $\mathbf{E}$ & $\mathbf{F}$ & $\mathbf{E} \rightarrow \mathbf{F}$ & $(\mathbf{E} \rightarrow \mathbf{F}) \rightarrow \mathbf{F}$ \\
\hline 1 & 1 & 1 & 1 & 1 \\
2 & 1 & 0 & 0 & 1 \\
3 & 0 & 1 & 1 & 0 \\
4 & 0 & 0 & 1 & 0 \\
\hline
\end{tabular}

Because conditions in the third and fourth rows together, as the last column value of truth is false, these possibilities will be eliminated; then in terms of the first and second rows, if $\mathrm{E}$ are true, no matter whether $\mathrm{F}$ are true or false, the result will be true. We need to avoid a possible misunderstanding that the value of truth in functional explanation have not be affected by the later items, because causal results would derive from any assumption, which cause the fact that it become the invalid reasoning. Only the inference in the first row that both $\mathrm{E}$ and $\mathrm{F}$ have true value reflects the empirical facts.

Iterating the formula of functional explanation, we can acquire the following results:
(1) $(\mathrm{E} \rightarrow \mathrm{F}) \rightarrow \mathrm{F}$
(2) $((\mathrm{E} \rightarrow \mathrm{F}) \rightarrow \mathrm{F}) \rightarrow(\mathrm{E} \rightarrow \mathrm{F})$
(3) $(((\mathrm{E} \rightarrow \mathrm{F}) \rightarrow \mathrm{F}) \rightarrow(\mathrm{E} \rightarrow \mathrm{F})) \rightarrow(\mathrm{E} \rightarrow \mathrm{F}) \rightarrow \mathrm{F})$ 
The constant and temporal variable have been omitted from formulas. When a simplified functional explanation has been well established, it could be wholly as an antecedent in the next step, at the same time, the antecedent in the original formula would play the role of consequent in new proposition. This process could be repeated and it will always produce true sentences. To interpret empirical objects by this method, constants and temporal variable should be taken into consideration and this practice will be true in the meaning of truth-functions, since in functional explanation is of speciality, antecedent is a proposition, and the inference process starting with the accepted item, so that it is a self-sufficient circulation.

Two concepts of "production" and "relationships of production" are introduced into functional explanation. That is "the relationships of production are R category relationships at $t$, as the result of it is suit for the current productive force, in other words, the level of productive force at $t$ ", which means the productive force only determines the essence of relationships of production rather its whole features [14]. In comparison with the content written by Marx, it is clear this usage of productive force has been captured by historical materialism.

\section{Understanding Just in the Technology Perspective}

G. A. Cohen draws a conclusion that "the essence of the priority of productive force is interpreting relationships of production by virtue of functional explanation [13]" from historical materialism. There is a distinction should be pay attention to is that Marx's concept of productive force is not same as the productive power. The productive force means a capacity to commit oneself into material production, in which labours playing a role of subject in production, who devote themselves into the sensible and objective activity. In the process of production, the applied technology belongs to productive force, apart from labours. In evaluation of the relationships of production, it is essential to consider the current scientific level. During the high-level of science development period, production should be combined with science, which means "whether an item is or is not productive force is not contingent on its entity, while related to whether it can promote efficiency of production [13]". In the Marxist meaning, the relationship is not ownership in law rather practical dominance, which can control productive matters effectively.

When Marx confers the right of determination to productive force, it seems that there are other elements playing important role in the development of society, such as technology, which is regarded as ontology in empiricalism tradition. As the result of overcoming alienation of technology is premise of eliminating technology ontology, Cohen start with it. He analyses historical materialism by "universal" historical materialism and "limited" historical materialism. "In the first category, the development of material and economy explains the characteristic of spirit evolution. In another category, spirit phenomenon cannot determine material development has been emphasized merely. "Only at this moment, it uses materialism to interpret spirit phenomenon, otherwise, the barrier of material development would appear [17]." Cohen regards historical materialism as a theory that : (1) during the whole process of time, the productive force shows a rising inclination;(2) waves of social forms are due to whether they could serve to the above development. In the viewpoint of Cohen, there are two kinds of historical materialism:(1) the first is systematical development rotating around human productive force;(2)another kind is also systematical development, in which human productive force playing a special role.

The "systematisms" of productive development emphases its automatic inclination, which means technology can go ahead by itself to some extent. Technology, out of human control, controls human beings. The autonomy of technology has some following suggestions: firstly, as the force in historical process, technology determines the direction of ideology, so that it becoming criteria in social critique. Secondly, technology is one part inside historical system endowing the interacting to determine the trend in evolution. Then the limitation of interacting between material and spirit is that it is not the case that spirit determines material. Technology alienation also can be eliminated. By functional explanation, Cohen gives the proof for the limited historical materialism proposition, in which "premise" means "adapt" is one-direction action: "if $\mathrm{x}$ adapt to $\mathrm{y}$, then $\mathrm{y}$ do not need to adapt to $x[14] . "$ The systematic development of productive force plays the preliminary role in all elements, under this condition, as the result of one-direction adaption and productive force has been blocked to go backwards, the historical process showing evolutionary feature. In this meaning, Cohen verifies the premise proposition that "there is a certain inclination of productive force throughout history."

Both the nature of kindness and the capacity of rational choice give opportunity to people for modifying their habitats to adapt to life. Iin spite of science has serving effects on human life; it also causes a series problems. The capitalism society, depending on science, possesses substantial material products and vast social capital with large gap of wealth among different people; in the market without management, the property has double implications:(1)the economic ability and power structure based on capital; (2)new power structure causes material productive elements are distributed unequally, thus some people who do not have necessary elements or who only hold partial material resources have no choice but to devote themselves into reluctant work. Cohen started to rethink historical materialism from the viewpoint of philosophical anthropology: as the core of history development, human beings are both energy and narrator of history. Marx has emphasized people are at the centre of productive force, implying dimension of function. Cohen, however, notices human life relies on their own communities, which are defined by race, nationality, and religions apart from economic elements, so that the reason why communities can exist is because they meet the self-identity 
of people. The spirit of community directs market into the right path. Because so-called free market does not have freedom in fact, which means if we hope to pursuit freedom and just in current conditions, we will not only need to develop technology, but also to carry out social critique.

\section{The Social Critique of Just}

The aim of social critique is to compromise Marxism with formal philosophy for unifying freedom, equality and just in society. Historical materialism reveal the crux in history, while laws and essence explored by formal philosophy, as its metaphysics principles, are of universal and inevitable assumption. Cohen's work looks like establishing a formal system, in which the just principle is constant. System designing and moral construction as variables are embedded into it through following process: (1) just principle reflects in practical situations; (2) and inlet empirical events into principles to acquire appropriate realizing scheme.

\subsection{Compatibility Between Freedom and Equality}

Equality and freedom are the common pursuit of human beings, however, whether the glorious ideals could be achieved basing on current social conditions rather than in remote future? It is essential to bear in mind that current capitalism society has strong self-modifying capacity, which has eliminated the revolutionary possibility among the public. Economic crisis makes people loose adequate certainty to assure that by developing technical can create infinite surplus value. As practical situation has been different from Marxist assumption, so that Cohen acknowledge we could realize socialism just ideal by means of system designing and moral education.

We hope in the just society, individuals are able to devote themselves into works with own will and individual growth can construct the condition for others free development. Cohen intend to find out a reasonable distribution scheme, which can promote productive development and compromise freedom with equality. He adapts a strategy by modifying theory of Robert Nozick. Nozick supposes just is adequate condition for freedom, because just society deriving from original freedom. However, practical illiberality and unequal phenomenon are result of natural development, so that we should hold tolerant attitude towards it. In spite of Nozick defend for illiberality and inequality; differences in talent and family background have not determined unequal results. Starting from this point, Cohen acknowledges that we have obligation to construct equal philosophy of politics in the relative poor era. In a more specific meaning, we could establish communities to break the limitations endowed by individual families, then people with same ability can acquire equal chance to pursuit their own sufficient development conditions. This also makes requirements for people that they should give up the motivation of "adaptive preference" just and insist principles of communities, serving for each other's needs.

Nozick believes that freedom and equality are contrary to each other. He defends for inequality from two premise:(1) "self-ownership"; (2) nobody can own the natural outer world to themselves. Everyone, who own themselves, devote their labor into outer world, so that the products containing labour of people [15]. Nozick puts forward the condition of if anyone intend to occupy the object $\mathrm{O}$, which has no owner and can be possessed by every people is that the object $\mathrm{O}$ exits from public field but it does not make prospect of other people to be worse. While Locke proposed, conditions of ownership includes:(1)individuals can occupy the products that containing their work;(2) they have to leave enough good things for other people;(3) at the same time they have not wasted what they acquired. Above all, Nozick weakens "Locke's conditions", because he did not emphasis the first and the third conditions. As the result of Nozick ignored several anti-facts situations, the inequality is not the inevitable outcome deriving from "self-ownership" [10]. Liberals and socialists issue two criteria for freedom and just. Regarding to liberals, who starting from original equality, reconcile it is acceptable that a bit of inequality existing in resources distribution. On the other hand, Cohen designs a new strategy that to construct rational system basing on empirical changes to maintain dynamic equality. In order to realize the scheme, he has designed Able and Infirm model to interpret that the compatibility between union ownership and self-ownership. Society is constituted by the Able and the Infirm in accordance with their productive capacity. The vote is held by the Infirm, which means whatever Able want to product must achieve agreement from the counterpart. At the same time, it is essential to check the Infirm group to rule out the possibility some Able hide in it, so social production efficiency can reach the adequate level. The vitality of co-ownership lies in the consensus of goodness. In a society the Infirm and the Able can convert to each other at different time, in other words, the current Infirm may convert to the Able some years later, vice verse. In spite of there is still competition in the communities, every competitor will not be abandoned as the result of failure in the competition. Liberals, however, hold the point that if union ownership mix with self-ownership, then the later will be eliminated.

Assuming the union self-ownership is $\mathrm{C}(\mathrm{x})$ and ownership is $\mathrm{S}(\mathrm{x})$, formal ownership is $\mathrm{F}(\mathrm{x})$ and practical ownership is $\mathrm{P}(\mathrm{x})$, veto power is $\mathrm{D}(\mathrm{x})$, doing nothing is $\mathrm{N}(\mathrm{x})$. Then the point of Nozick can be presented as following:

$\mathrm{C}(\mathrm{A}, \mathrm{I}) \wedge \mathrm{S}(\mathrm{A}, \mathrm{I}) \rightarrow \mathrm{F}(\mathrm{S}(\mathrm{A}))$

$\mathrm{C}(\mathrm{A}, \mathrm{I}) \wedge \mathrm{S}(\mathrm{A}, \mathrm{I})$

$\mathrm{F}(\mathrm{S}(\mathrm{A}))$

Nozick points that if union ownership and self-ownership are contrary to each other, in addition to union ownership is dominant, then self-ownership has been denied.. While Cohen hold different viewpoint that self-ownership is compatible with union ownership, in other words, practical self-ownership does not exclude vote power( $\mathrm{P}(\mathrm{S}(\mathrm{A}, \mathrm{I}))$ $\wedge \mathrm{D}(\mathrm{I}))$.

$$
\begin{aligned}
& \text { 1. } \mathrm{D}(\mathrm{I}) \wedge \mathrm{F}(\mathrm{S}(\mathrm{A})) \rightarrow \mathrm{N}(\mathrm{A}) \\
& \neg \mathrm{N}(\mathrm{A}) \\
& \neg(\mathrm{D}(\mathrm{I}) \wedge \mathrm{F}(\mathrm{S}(\mathrm{A})))
\end{aligned}
$$




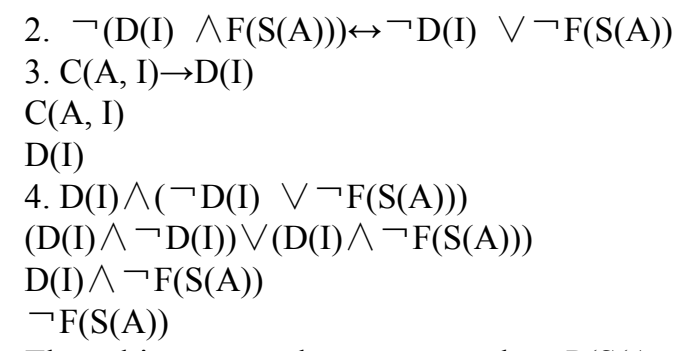

The ultimate result represent that $\mathrm{P}(\mathrm{S}(\mathrm{A}, \mathrm{I}))$ [15] is well-established. When we demonstrate two ownership system can be harmony with each other, the liberty can co-exist with equality in a possible world.

\subsection{System Designing of Justice and Equality}

Rawls hopes to seek out a universal meaning of justice with internalist implicature. It is able to maintain fixed cooperation, because individuals may be on guard for their own interest against others in absolutely situation. The contract is conducted behind the veil of ignorance, that can products just system by means of rational allocation of rights and obligation. When the conflicts of interests happen, it can still keep the society in balance. In the process of allocation, the "the Difference Principle", the unequal distribution in economy field is of permissibility only if it maximizes the benefits of the least favored [13]. Cohen, however, [2] thinks the so-called "the Difference Principle" is in defense of inequality in nature. Rawls designs just social system in accordance with the spirit basing on "veil of ignorance". This kind of constructivism justice substitutes "what is justice" with "how to formulate ideal social management rule". As limited by practical environment, the public have sway away from pure justice and this change causing injustice. Apart from it material stimulation strategy have meet the requirement of "the Difference Principle": the Able devote themselves into social progress and they should be paid corresponding salaries. Because the whole development of society will be benefit for modify living situation for the poor. On the other hand, as the result of struggling for life, the poor must endure tough life causing by the gap of wealth, thus the stimulating mechanism in "the Difference Principle" compromise with selfish character shaped by capitalism calmly. It is vital that modifying only represents increments, in other words, the weaker still have to rely on the wealthy people for living, and the original inequality will increase in an exponent way as time goes by.

In terms of Cohen's view, the equality between the poor and the wealthy is still a remote ideal under "the Difference Principle", so that the socialism opportunity equality could be a reasonable alternative, because it merely contains difference in intended choices, which means the inequality caused by variety of choices and preferences. In "why not socialism" Cohen constructs camping trip model to check reciprocal and sharing principle. During the trip everyone has opportunity to go through glorious time with each other by sharing private goods, serving for others with unique talent, and cooperating in accordance with their willing, so that they can become reciprocal friends without worries about struggling for living. The reason why camping trip is glorious locates in equality, the more specific expression is socialism opportunity equality and sharing can realize in it. In order to realize equality we have to wipe away the chance barriers undertaken by the partial. There are also two kinds of chance equality. The first is capitalist chance equality that enlarges the public opportunity by eliminating limitation caused by social idea from right allocation and prejudice [2]. Another is liberalism equality, rejecting inequality deriving from family background, claim to gift and free choice determine individual destiny. While socialism opportunity equality avoids inequality from different talents as well as negative result caused by inevitable conditions. Difference can only reflect interests and choices. In the camping trip people accept inequality in a limited field. Then when we enlarge it to the market, the inequality also increase correspondingly. As it said that "market is inevitable" [2]. Socialism opportunity equal should be improved by sharing principle, that people take care of their companions in the context of market. The purpose and the aim has be tied together, in which "wiling "is the motivation of all actions, thus the inner motivation rooted in the good nature. Cohen hopes to figure out the crux from selfishness and limited technology in the category of socialism equality. Eventually, he attributed the problem to the ignorance of how to use and develop general character to run the market. There is an eclectic method that "inlet strong sharing and equal spirit into selfish choice, at the same time the latest element must be controlled [2]". This is market socialism.

By means of critique theory of Nozick and Rawls, Cohen demonstrates that the equality compatible with freedom and justice respectively. Therefore, just society implies equality, freedom as well as justice, which has been a well-established premise. Cohen's inspiration enriches the meaning of just. During the process of realizing just ideal, we should not only put forward science and technology reaching higher stage, but also convert the motivation of public, planting individual will into mutual service. The journey to just starts with virtuous kindness from heart.

\section{References}

[1] Cohen, G., 1994. Back to Socialist Basics. New Left Review, 0(207), pp. 3-16.

[2] Cohen, G., 2011. Why not Socialism? Beijing: Renmin press.

[3] Cohen, G. A., 1966. Beliefs and Roles. London, Oxford University Press.

[4] G. A. Cohen, 1989. On the Currency of Egalitarian Justice. Ethics, 99(4), pp. 906-944.

[5] G. A. Cohen, 1995. The Pareto Argument for Inequality. Social Philosophy and Policy Foundation, 12(1), pp. 160-185.

[6] G. A. Cohen, 1997. Where the Action is: On the Site of Distributive Justice. Philosophy \& Public Affairs, 26(1), pp. 3-30.

[7] G. A. Cohen, 2000. If You're an Egalitarian, How Come You're 
so Rich?. The Journal of Ethics, 4(1/2), pp. 1-26.

[8] G. A. Cohen, 2003. Facts and Principles. Philosophy \& Public Affairs, 31(3), pp. 211-245.

[9] G. A. Cohen, 2006. Review: Luck and Equality: A Reply to Hurley. Philosophy and Phenomenological Research, 72(2), pp. 439-446.

[10] G. A. Cohen, 2008. Self-ownership, Freedom and Equality. Beijing: Oriental press.

[11] Gerald A. Cohen and H. B. Acton, 1970. Symposium: On Some Criticism of Historical Materialism. Proceedings of the Aristotelian Society, Volume 44, pp. 121-156.

[12] Hume, D., 2009. A Treatise of Human Nature. Beijing: the commercial press.

[13] Qiao Ruijin, et al., 2013. The British Neo-Marxism. Beijing: Renmin press.
[14] Wei, C., 2008. On Cohen's ' primary life problem'. Lanzhou Academic Journal, 4(175).

[15] Zhongqiao, D., 2013. A Criticism of Libertarianism from the Socialist Perspective: G. A. Cohen's Rebute of Robert

[16] Nozick's ' self-ownership' proposition. Social Sciences in China, Issue 11.

[17] Zhongqiao, D., 2013. G. A. Cohen's Reconsideration of Historical Materialism. Philosophical Researches, Issue 2, pp. 21-28.

[18] Zhongqiao, D., 2013. G. A. Cohen's defense of Three Basic Problems in Historical Materialism. Hebei Academic Journal, 33(2), pp. 29-34. 